\title{
Can children undergoing ophthalmologic examinations under anesthesia be safely anesthetized without using an IV line?
}

This article was published in the following Dove Press journal:

Clinical Ophthalmology

19 April 201 I

Number of times this article has been viewed

Michael MVigoda

Azeema Latiff

Timothy G Murray

Jacqueline L Tutiven

Audina M Berrocal

Steven Gayer

Bascom Palmer Eye Institute, University of Miami Miller School of Medicine, Miami, FL, USA
Correspondence: Timothy G Murray University of Miami/Bascom Palmer Eye Institute, 900 NW 17th Street, Miami, FL 33136, USA

Tel +l 3053266166

Fax +l 3055473713

Email tmurray@med.miami.edu
Purpose: To document that with proper patient and procedure selection, children undergoing general inhalational anesthesia for ophthalmologic exams (with or without photos, ultrasound, laser treatment, peri-ocular injection of chemotherapy, suture removal, and/or replacement of ocular prosthesis) can be safely anesthetized without the use of an intravenous (IV) line. Children are rarely anesthetized without IV access placement. We performed a retrospective study to determine our incidence of IV access placement during examinations under anesthesia (EUA) and the incidence of adverse events that required intraoperative IV access placement.

Methods: Data collected from our operating room (OR) information system includes but is not limited to diagnosis, anesthesiologist, surgeon, and location of IV catheter (if applicable), patient's date of birth, actual procedure, and anesthesia/procedure times. We reviewed the OR and anesthetic records of children ( $>1$ month and $<10$ years) who underwent EUAs between January 1, 2003 and May 31, 2009. We determined the percentage of children who were anesthetized without IV access placement, as well as the incidence of any adverse events that required IV access placement, intraoperatively.

Results: We analyzed data from 3196 procedures performed during a 77-month period. Patients' ages ranged from 1 month to 9 years. Overall, 92\% of procedures were performed without IV access placement. Procedure duration ranged from 1-39 minutes. Reasons for IV access placement included parental preference for antinausea medication and/or attending preference for IV access placement. No child who underwent anesthesia without an IV line had an intraoperative adverse event requiring insertion of an IV line.

Conclusion: Our data suggest that for children undergoing general anesthesia for ophthalmologic exams (with or without photos, ultrasound, laser treatment, intraocular injection of chemotherapy, suture removal, and/or replacement of ocular prosthesis), anesthesia can be safely conducted without placement of an IV line.

Keywords: IV access placement, anesthesia, chemotherapy, general anesthesia, children

\section{Introduction}

General anesthesia is rarely administered in children without ensuring intravenous (IV) access. This issue of when, and whether, to obtain IV access in an anesthetized child has triggered much debate over the past years and remains controversial. ${ }^{1,2}$ The only procedure where IV access is not routinely obtained is in placement of tympanostomy tubes. In many instances, multiple IV cannulation attempts will outlast the proposed period of the surgical procedure/intervention. Numerous pediatric centers perform outpatient dental extractions and minor ENT (ear, nose, and throat) procedures without compulsory IV access. ${ }^{2-4}$ For brief, minimally invasive ophthalmologic procedures including examinations under anesthesia (EUAs), some anesthesiologists may elect 
to forego IV access in children. Recently, a listserve group composed of an international group of academic anesthesiologists (from the United States, the United Kingdom, France, Brazil, Argentina, South Africa, Egypt, India, and New Zealand) addressed this issue. The ensuing discussion thread indicated a marked difference of opinion between those who asserted that IV access is mandatory and those who maintained it was optional. For example, in Ilorin, Nigeria a retrospective study of 39 children underwent EUAs without IV access during an 18-year period. Of this group, 36 children $(92.3 \%)$ had inhalational anesthesia administered as the anesthetic of choice, ${ }^{5}$ thus providing initial evidence of common practice utilizing inhalational anesthesia in the African continent.

\section{Materials and methods}

This study was approved by the University Of Miami Miller School Of Medicine's Institutional Review Board. Our operating room (OR) information system was developed inhouse for both case scheduling as well as for recording nursing documentation. For all OR cases, data collection includes (but is not limited to) diagnosis, anesthesiologist, surgeon, patient's date of birth, actual procedure, anesthesia and procedure start/end times, and the location of IV catheter, if applicable. We reviewed the OR records of children older than 1 month but less than 10 years of age who underwent an examination under anesthesia between January 1, 2003 and May 31, 2009.

We excluded procedures that involved an EUA as part of a more comprehensive procedure or which may have led to a surgical procedure during the time the child was anesthetized. For example, if the scheduled procedure was EUA with possible trabeculotomy or vitrectomy, we excluded the procedure. The set of procedures included were EUAs, with or without photos, ultrasound, laser treatment, intraocular injection of chemotherapy, suture removal, and/or replacement of ocular prosthesis.

We restricted our analysis to children who were cared for by the retina service, as this service's volume in the OR for children under 10 years of age is approximately 40-60 procedures per month, with a typical anesthetic duration of 20 minutes for EUAs. Other services (eg, glaucoma, oculoplastics, strabismus) did not have a sufficient volume of patients to exclude the role of the ophthalmologist as a factor in whether or not a child would undergo an EUA without an IV line in place.

For those records that indicated IV access placement, we reviewed the anesthetic record to determine time of placement and whether the placement occurred as a result of an adverse anesthetic event or for some other reason (eg, patient had a history of postoperative nausea and vomiting and parents desired an anti-emetic to be administered intravenously).

\section{Results}

In 92\% (2949) of the 3196 cases that were reviewed, general anesthesia was performed without IV access (Table 1). In the $8 \%$ (241) of cases IV access, this typically occurred in the OR (ie, $80 \%$ of the time or in 193 instances). We could not identify the specific time where $11 \%$ (27) of IV access placements occurred (Table 2). We considered that no IV access placement occurred in the 14 cases where IV access placement was documented in the nursing record but not in the anesthetic record.

Our patient population ranged from 1 month to 9 years, with $58 \%$ of patients $<3$ years of age and $75 \%<4$ years of age (Table 3), IV access placement was slightly more common at the age extremes of our population (Figure 1).

Procedure duration ranged from 1-39 minutes (Figure 2), with IV access placement more common in procedures lasting over 35 minutes (Figure 3). The only adverse event occurred in a 177-day-old child with trisomy 21 who received intramuscular atropine on inhalation induction because of bradycardia. (Heart rate was 75 when atropine was administered).

\section{Discussion}

Our data indicate that it is possible to safely anesthetize children (the majority of whom were $<3$ years of age) for ophthalmic EUAs. We do not consider our results to necessarily reflect an ability to provide better care. Rather, we believe that our results speak to the value of establishing

Table I IV access placement by year of procedure

\begin{tabular}{lllll}
\hline Year & $\begin{array}{l}\text { Total } \\
\text { procedures }\end{array}$ & $\begin{array}{l}\text { Patients anesthetized } \\
\text { without an IV line }\end{array}$ & IV line & $\begin{array}{l}\text { Central } \\
\text { line }\end{array}$ \\
\hline 2003 & 367 & $320(87 \%)$ & 45 & 2 \\
2004 & 408 & $378(93 \%)$ & 30 & 0 \\
2005 & 388 & $361(93 \%)$ & 27 & 0 \\
2006 & 526 & $487(93 \%)$ & 38 & I \\
2007 & 630 & $579(92 \%)$ & 50 & 1 \\
2008 & 592 & $556(94 \%)$ & 34 & 2 \\
2009 & 285 & $268(94 \%)$ & 17 & 0 \\
Total & 3196 & $2949(92 \%)$ & 241 & 6 \\
\hline
\end{tabular}

Note: Six patients came to the OR with their central lines accessed. There were 14 cases where IV access was documented on the nursing records, but review of the anesthesia record had no notation of IV access placement. There were also no recordings of medications given. We classified these cases as having no IV access placement.

Abbreviations: IV, intravenous; OR, operating room. 
Table 2 IV access placement by location

\begin{tabular}{lllll}
\hline Year & $\begin{array}{l}\text { Number of patients with } \\
\text { an IV line }\end{array}$ & $\begin{array}{l}\text { IV access placed } \\
\text { in OR }\end{array}$ & $\begin{array}{l}\text { IV access placed } \\
\text { prior to OR }\end{array}$ & $\begin{array}{l}\text { IV start time } \\
\text { not recorded }\end{array}$ \\
\hline 2003 & 45 & 38 & 1 & 6 \\
2004 & 30 & 25 & 4 & I \\
2005 & 27 & 19 & 2 & 6 \\
2006 & 38 & 32 & 1 & 5 \\
2007 & 50 & 46 & 0 & 4 \\
2008 & 34 & 21 & 8 & 5 \\
2009 & 17 & 12 & 5 & 0 \\
Total & 241 & 193 & 21 & 27 \\
\hline
\end{tabular}

Abbreviations: IV, intravenous; OR, operating room

a structured intraoperative plan as well as a constructive teamwork milieu amongst physicians and our nursing staff. In comparison, the exact opposite approach was used in a comparative study of two anesthesia techniques for pediatric refractive surgery, whereby all 30 participants in the study had IV access placement with utilization of either propofol/ fentanyl and ketamine/midazolam anesthesia. ${ }^{6}$ We feel this approach offers no benefit to our unique patient environment since we have the ability to provide all the necessary services within our operating theater environment. Therefore, we do not have to make exceptions as to anesthesia choice based on access to the operating theater unlike our colleagues who practice in a non-OR environment.

Prior to 2004, five different anesthesiologists supervised ophthalmic EUAs. For a variety of reasons (eg, desire for standardization of anesthetic care, anesthesiologist's preference to be involved with these types of cases), this arrangement changed in 2004. Since 2004, two pediatric anesthesiologists (MV, JT) have been responsible for $>98 \%$ of these cases. All EUAs were performed by two pediatric ophthalmologists (AB, TM). We have previously emphasized the value of teamwork in a previous publication describing our progressive improvement in decreasing the mean turnover time from 12.1 minutes to 3.8 minutes, despite an ongoing increase in the number of cases per day. ${ }^{7}$

In a study from Royal Aberdeen Children's Hospital, they also documented the effectiveness of avoiding IV access placement for children undergoing short procedures evaluating their experience since $2005 .{ }^{8}$

Children with retinal diseases need serial follow-up examinations and return with some regularity for EUA. ${ }^{9}$ Families may reside at considerable distance or parents may become dismissive of the value of pre-anesthesia evaluation prior to the day of surgery. We prescreen patients via telephone and provide NPO (nil per os) orders. In general, younger children are scheduled earlier in the day to minimize prolonged NPO status. While waiting their turn in the holding room, the pediatric anesthesiologist documents preoperative assessment. Some children may receive an anxiolytic (midazolam, $0.5 \mathrm{mg} / \mathrm{kg}$ ) orally. Premedication with midazolam prolongs neither emergence from general anesthesia nor discharge from the hospital. ${ }^{10}$

While clinical predictors of potential perioperative events (eg, upper respiratory infections, cough) enter into

Table 3 Procedure duration (in minutes) by patient age

\begin{tabular}{|c|c|c|c|c|c|c|}
\hline Age & 25th percentile & 50th percentile & 75th percentile & Minimum & Maximum & $\mathbf{N}$ \\
\hline$<3$ months & 16 & 24 & 30 & 10 & 39 & 43 \\
\hline$<6$ months & 12 & 18 & 22 & 3 & 39 & 127 \\
\hline$<9$ months & 11 & 16 & 21 & 3 & 38 & 183 \\
\hline$<$ I year & 10 & 16 & 22 & 3 & 39 & 199 \\
\hline I year & 10 & 16 & 21 & 1 & 39 & 760 \\
\hline 2 years & 10 & 14 & 19 & I & 39 & 560 \\
\hline 3 years & 9 & 13 & 17 & 1 & 38 & 518 \\
\hline 4 years & 9 & 12 & 16 & 1 & 35 & 352 \\
\hline 5 years & 9 & 12 & 16 & 1 & 39 & 193 \\
\hline 6 years & 11 & 14 & 17 & 2 & 33 & 112 \\
\hline 7 years & 12 & 15 & 19 & I & 37 & 94 \\
\hline 8 years & 11 & 14 & 18 & 5 & 35 & 47 \\
\hline 9 years & 12 & 16 & 21 & 5 & 33 & 8 \\
\hline
\end{tabular}

Note: Patients $<$ I month were excluded as there were only five cases. 


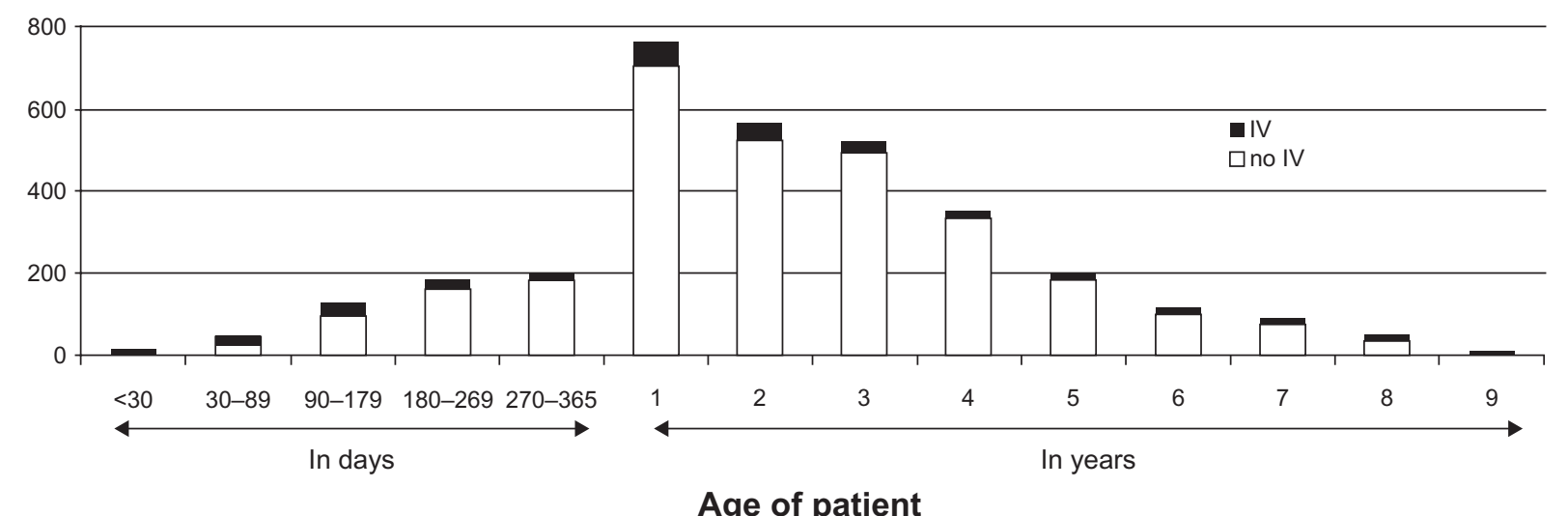

Figure I Number of procedures by patient age.

Abbreviation: IV, intravenous line.

the decision making for children scheduled to receive general anesthesia, the risk/benefit ratio as it relates to children with retinal tumors typically implies that it is extremely rare for a procedure to be postponed. There is very little data available assessing the actual risk of IV access not being available during general anesthesia. The greatest threat may be the risk of pulmonary aspiration in any child undergoing inhalational induction without IV access. Borland et al reported the incidence of aspiration in children to be 52/50,330 cases, with 29 $(0.05 \%)$ requiring intubation and/or extended hospital stay. ${ }^{11}$ Likewise, Warner et al reported the risk of pulmonary aspiration to be 1 in $8000(0.0125 \%)$ children. ${ }^{12}$ Because of the integrated team approach used by our pediatric anesthesia team, any child who is deemed necessary to receive IV access has an IV line placed prior to ophthalmological examination.

Some parents expressed concerns about postoperative nausea and vomiting, either because their child had intraocular chemotherapy or because of the child's history of postoperative nausea and vomiting. When a parent requested IV access placement for administration of anti-emetic medication, we placed an IV line after inhalation induction. When older children preferred an IV induction because of previous unpleasant experiences with inhalation induction, IV access placement was performed in the holding area.

Parents accompany the child into the OR and frequently participate in the inhalation induction. ${ }^{13}$ Inhalation induction circumvents children's natural aversion to needles. A smooth, atraumatic induction of general anesthesia may reduce the incidence of postoperative dysphoria and longterm emotional sequelae. ${ }^{14}$ Once their child is asleep, parents are escorted to the waiting rooms.

We routinely calculate atropine, epinephrine, and succinylcholine doses and have them immediately available for intramuscular or IV administration should bradycardia or laryngospasm occur during the procedure. Additionally, an IV line, cannula, and starter kit are readied and placed

\section{Duration of surgical procedure (minutes)}

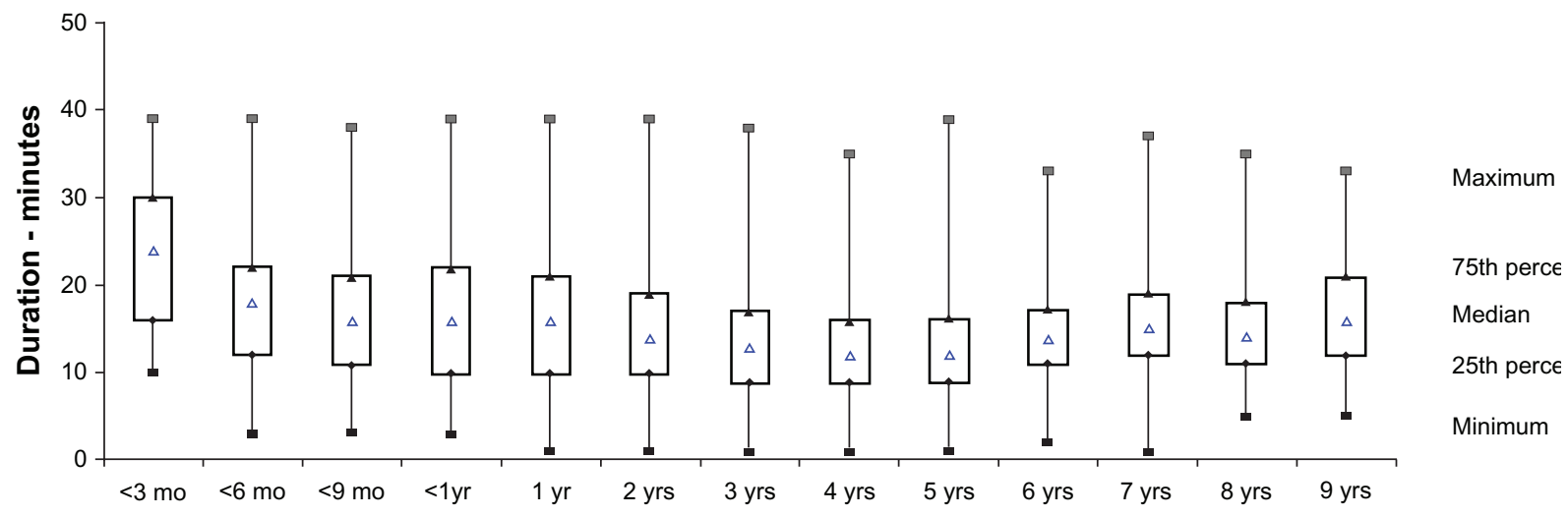

Figure 2 Procedure duration (in minutes) by patient age. Abbreviations: mo, month; $y r$, year. 


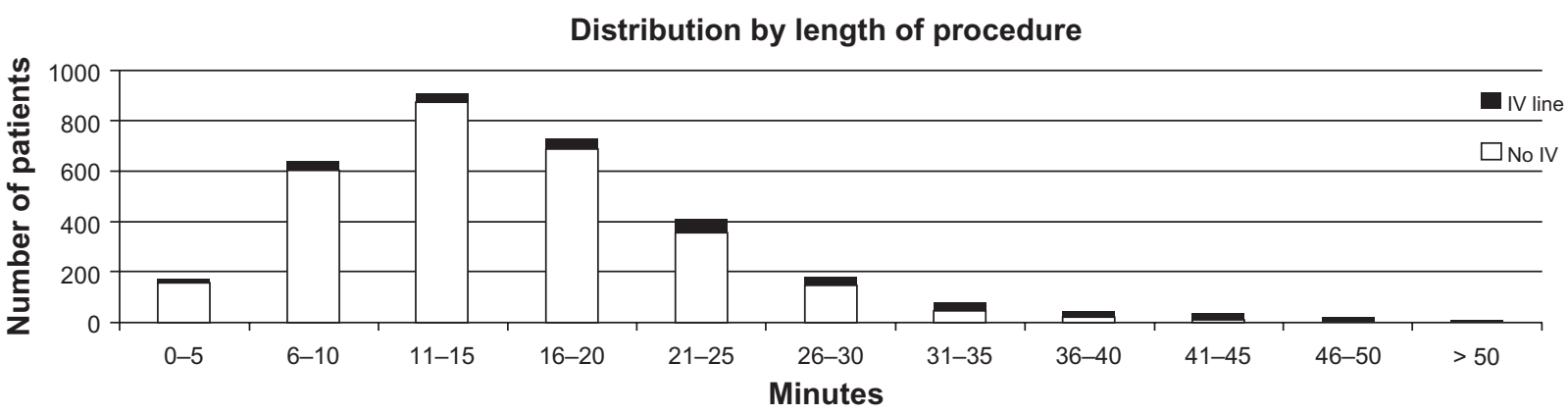

Figure 3 IV access placement as a function of procedure duration. Abbreviation: IV, intravenous.

proximate to each patient prior to commencing anesthesia. The airway is maintained via facemask and adequate depth of anesthesia is assured prior to any manipulation of the eye to preclude instigation of laryngospasm or oculocardiac reflex. The position of the globe within the orbit is a key indicator of anesthetic depth. Bell's phenomenon is a natural protective reflex in which the globe turns cephalad in response to pressure on the eye by a lid speculum..$^{15,16}$ This occurs both in the awake state and with light planes of anesthesia. In contrast, the reflex is extinguished with deep planes of anaesthesia such that the eye remains in neutral gaze. Observation of these and other signs as well as good communication between ophthalmologists, technicians, and anesthetists is a key component to ensure favourable outcome.

Pupil dilation improves the quality of the exam and photography. Mydriatics have long latency of onset, so additional drops may be instilled in the OR in attempt to improve inadequate dilation. These agents can drift through the puncta into the nasolacrimal duct and be systemically absorbed via the nasal mucosa. The alpha agonist mydriatic phenylephrine can create transient hypertension, pulmonary edema, or even cardiac arrest. ${ }^{17}$ Therefore, we avoid full strength, $10 \%$ phenylephrine in favor of other parasympatholytic mydriatic agents, or judicious use of $2.5 \%$ phenylephrine with active digital occlusion of the puncta. ${ }^{18}$

Previous studies have shown that IV access placement after induction of anesthesia for short duration pediatric myringotomy increases time in the OR and produces more postoperative analgesic requirements, and leads to lower parental satisfaction, than anesthesia without IV access. ${ }^{19}$ While acknowledging the inherent deficiencies of retrospective analysis, our data affirm that mask anesthesia without IV access for brief EUAs in children with retinal diseases can be safely accomplished.

In conclusion, this study documents the ability to safely forego mandatory IV access and supports the use of masked inhalational induction in the pediatric ophthalmologic patient We believe these findings have significant implications for management in all pediatric cases undergoing general inhalational anesthesia support. Acknowledgement that this technique has limitations is imperative and demands experienced personnel who are trained to work with children. The data offer possibilities for a future discussion on whether anesthesia can be securely delivered for brief procedures without IV access. ${ }^{8}$

\section{Reprints}

No reprints will be made available.

\section{Financial support}

The study was internally funded by departmental sources.

\section{Disclosure}

None of the authors report a conflict of interest.

\section{References}

1. Martin R. Instrumentation of the airway in the absence of intravenous access. Paediatr Anaesth. 2003;13:366.

2. Stewart P. Airway management without i.v. access - bad practice or a technique with potential? Paediatr Anaesth. 2003;13:744-745.

3. MacMillan CS, Wildsmith JA. A survey of paediatric dental anaesthesia in Scotland. Anaesthesia. 2000;55:581-586.

4. Allen AH. Is i.v. access necessary for myringotomy with tubes? Ear Nose Throat J. 2007;86:672-674, 681.

5. Mahmoud AO, Ayanniyi AA, Oyedepo OO. Pediatric ophthalmic indications for examination under anesthesia in Ilorin, Nigeria. Ann Afr Med. 9:181-183.

6. Mahfouz AK, Khalaf MA. Comparative study of 2 anesthesia techniques for pediatric refractive surgery. J Cataract Refract Surg. 2005;31: 2345-2349.

7. Vigoda MM, Gayer S, Tutiven J, et al. Targeting operating room inefficiencies in the complex management of vision-threatening diseases in children. Arch Ophthalmol. 2008;126:1241-1243.

8. Wilson G, Engelhardt T. Who needs an IV? Retrospective service analysis in a tertiary pediatric hospital. Paediatr Anaesth. Epub 2010 Dec 28.

9. Saito T, Endo M, Hiraga K, Kaneko A. Clinical trial of fundoscopy under general anesthesia for pediatric outpatients with retinoblastoma. Int J Clin Oncol. 2004;9:36-41. 
10. Brosius KK, Bannister CF. Effect of oral midazolam premedication on the awakening concentration of sevoflurane, recovery times and bispectral index in children. Paediatr Anaesth. 2001;11:585-590.

11. Borland LM, Sereika SM, Woelfel SK, et al. Pulmonary aspiration in pediatric patients during general anesthesia: incidence and outcome. J Clin Anesth. 1998;10:95-102.

12. Warner MA, Warner ME, Warner DO, Warner LO, Warner EJ. Perioperative pulmonary aspiration in infants and children. Anesthesiology. 1999;90:66-71.

13. Kain ZN, Caldwell-Andrews AA, Krivutza DM, Weinberg ME, Wang SM, Gaal D. Trends in the practice of parental presence during induction of anesthesia and the use of preoperative sedative premedication in the United States, 1995-2002: results of a follow-up national survey. Anesth Analg. 2004;98:1252-1259, table of contents.

14. Meyers EF, Muravchick S. Anesthesia induction technics in pediatric patients: a controlled study of behavioral consequences. Anesth Analg. 1977;56:538-542.
15. Francis IC, Loughhead JA. Bell's phenomenon. A study of 508 patients. Aust J Ophthalmol. 1984;12:15-21.

16. Bell C, Shaw A. Reprint of the "Idea of a New Anatomy of the Brain", with Letters, \&c. J Anat Physiol. 1868;3:147-182.

17. Greher M, Hartmann T, Winkler M, Zimpfer M, Crabnor CM. Hypertension and pulmonary edema associated with subconjunctival phenylephrine in a 2-month-old child during cataract extraction. Anesthesiology. 1998;88:1394-1396.

18. Fraunfelder FT, Scafidi AF. Possible adverse effects from topical ocular 10\% phenylephrine. Am J Ophthalmol. 1978;85:447-453.

19. Haupert MS, Pascual C, Mohan A, Bartecka-Skrzypek B, Zestos MM. Parental satisfaction with anesthesia without intravenous access for myringotomy. Arch Otolaryngol Head Neck Surg. 2004;130: $1025-1028$.
Clinical Ophthalmology

\section{Publish your work in this journal}

Clinical Ophthalmology is an international, peer-reviewed journal covering all subspecialties within ophthalmology. Key topics include: Optometry; Visual science; Pharmacology and drug therapy in eye diseases; Basic Sciences; Primary and Secondary eye care; Patient Safety and Quality of Care Improvements. This journal is indexed on

\section{Dovepress}

PubMed Central and CAS, and is the official journal of The Society of Clinical Ophthalmology (SCO). The manuscript management system is completely online and includes a very quick and fair peer-review system, which is all easy to use. Visit http://www.dovepress.com/ testimonials.php to read real quotes from published authors. 